\title{
Relationship between tumor size and disease stage in non-small cell lung cancer
}

\author{
Fu Yang ${ }^{1,2}$, Haiquan Chen ${ }^{1,2^{*}}$, Jiaqing Xiang ${ }^{1,2}$, Yawei Zhang ${ }^{1,2}$, Jianhua Zhou ${ }^{1,2}$, Hong Hu $^{1,2}$, Jie Zhang ${ }^{1,2}$, \\ Xiaoyang Luo ${ }^{1,2}$
}

\begin{abstract}
Background: Whether tumor size and stage distribution are correlated remains controversial. The objective is to assess the relationship between tumor size and disease stage distribution in non-small cell lung cancer (NSCLC).

Methods: We conducted a retrospective analysis of 917 cases of NSCLC that were resected in the Cancer Hospital of Fudan University and Shanghai Sixth Hospital between January 2000 and February 2009. Tumor sizes were grouped into five categories: $\leq 20 \mathrm{~mm}, 21$ to $30 \mathrm{~mm}, 31$ to $50 \mathrm{~mm}, 51$ to $70 \mathrm{~mm}$ and $\geq 71 \mathrm{~mm}$.

Results: Age and tumor size affected stage distribution: patients 60 years or older had a higher percentage of NOM0 disease than patients younger than 60 years $(61.67 \%$ vs. $44.85 \%, p<0.01)$. The smaller the tumor, the more likely the disease was NOMO status $(p<0.05)$. For tumors $\leq 20 \mathrm{~mm}$ in diameter, the proportion of cases with NOMO status was $70.79 \%$, compared to $58.88 \%$ for 21 to $30 \mathrm{~mm}, 48.03 \%$ for 31 to $50 \mathrm{~mm}, 47.55 \%$ for 51 to $70 \mathrm{~mm}$, $33.33 \%$ for $\geq 71 \mathrm{~mm}$. The mean ( \pm SD) tumor size of cases with NOMO status was $37.17 \pm 21.34 \mathrm{~mm}$, compared to $45.75 \pm 23.19 \mathrm{~mm}$ for cases with other status.

Conclusions: There is a statistically significant relationship between tumor size and distribution of disease stage of primary NSCLC tumors: the smaller the tumor, the more likely the disease is NOMO status.
\end{abstract}

\section{Background}

Lung cancer is the leading cause of cancer-related death worldwide. A total of 497,908 new lung cancer cases and 428,938 deaths from lung cancer are estimated to have occurred in China in 2005 [1,2]. When diagnosis and treatment are initiated early, lung cancer can be cured. In the database of IASLC, the 5-year survival rate of patients with pathologic and clinical stage IA nonsmall cell lung cancer (NSCLC) is $73 \%$ and $50 \%$, respectively [3]. In contrast, the 5 -year survival is only $13 \%$ and $2 \%$ for patients with pathologic and clinical stage IV disease, respectively [3]. Unfortunately, 75\% 80\% patients with NSCLC are diagnosed with locally advanced or advanced disease [4], resulting in a dismal overall 5-year survival of $15.7 \%[5,6]$.

This state implies that to improve survival, efforts should be made to detect NSCLC in earlier stages so that curative surgery can be performed. Lung cancer

\footnotetext{
* Correspondence: hqchen1@yahoo.com

'Department of Thoracic Surgery, Fudan University Shanghai Cancer Center, 270 Dong'an Road, Shanghai 200032, China

Full list of author information is available at the end of the article
}

screening trials with conventional chest radiography have failed to decrease lung cancer mortality [7-9]. However, the use of low-dose helical computed tomography $(\mathrm{CT})$ scans has refueled the impetus to detect lung cancer at earlier stages. Compared to chest tomography, CT scans can detect non-calcified nodules three times more commonly and malignant nodules four times more often [10-12]. Advocates of low-dose CT screening believe that the smaller the lesion, the more likely it is to be in an early stage. Tumor size is an important characteristic of the $\mathrm{T}$ descriptors in the seventh edition of the TNM classification for lung cancer [3], but whether tumor size correlates with stage distribution in NSCLC remains controversial. This study was conducted to investigate the relationship between tumor size and stage distribution in nearly 1000 Chinese patients with resected NSCLC.

\section{Methods}

Between January 2000 and February 2009, 1083 patients underwent surgery with curative intent for primary NSCLC in the Cancer Hospital of Fudan University and 
the Shanghai Sixth Hospital. Inclusion criteria included complete pathologic staging according to the TNM classification system of the UICC/AJCC and adequate documentation of tumor size, the type of lymphadenectomy was systematic nodal dissection. Cases were retrospectively analyzed, and all data were obtained from the medical records, including gender, age, tumor location (right or left side, upper or lower or middle lobe), histology, tumor size, pathologic stage and the presence or absence of lymph node or distant metastases. Routine pre-operative examination included chest $\mathrm{CT}$, abdominal CT or ultrasonography or magnetic resonance imaging, brain $\mathrm{CT}$ or magnetic resonance imaging, and bone scanning. The final pathologic stage and the status of lymph node or distant metastases were determined based on pathology reports and clinical data. It was classified as N0 (no metastases), N1 (only ipsilateral peribronchial, hilar, and/or intrapulmonary metastases), N2 (ipsilateral mediastinal and/or subcarinal metastases, no contralateral), or N3 (contralateral mediastinal and/or hilar, scalene, or supraclavicular metastases). Status of distant metastases was classified as M0 (absent) or M1 (present). NOM0 status was defined as no metastases, other status were defined as metastases. Tumor size was defined by greatest diameter based on the pathology report. Histology was divided into five categories according to the 2004 World Health Organization classification of lung tumor: squamous cell carcinomas, adenocarcinomas, adenosquamous cell carcinomas, large cell carcinomas, and other histologic types of primary NSCLC. Totally 158 patients were excluded. 148 patients were excluded because of the type of lymphadenectomy was not systematic nodal dissection. 10 patients were excluded because of the tumor size was not clear from the pathology report. And 8 patients were excluded because of neoadjuvant chemotherapy or chemoradiotherapy. The remaining 917 cases were received lobectomy or pneumonectomy.

According to the revision of the $\mathrm{T}$ descriptors in the seventh edition of the TNM classification for lung cancer [13], we classify the 917 remaining cases of NSCLC into the following five tumor size categories according to the greatest diameter of tumor: $\leq 20 \mathrm{~mm}, 21 \sim 30 \mathrm{~mm}$, $31 \sim 50 \mathrm{~mm}, 51 \sim 70 \mathrm{~mm}$, and $\geq 71 \mathrm{~mm}$. We focused principally on the frequency of NOMO status in these categories. Tumor size was used as a continuous variable. Both parametric and nonparametric methods were used to compare stage distributions relative to tumor size. Univariate associations between disease stage and gender, age, location of tumor, histology, and tumor size were explored using $\chi^{2}$ tests. The independent effect of tumor size as categorical variables on disease stage was analyzed using a logistic regression model. All the analyses were conducted using the statistical software
(SPSS15.0). All P values are two sided and considered statistically significant when less than 0.05 .

The study was conducted in accordance with the principles of the Helsinki Declaration. And it was approved by the Ethics Committee of Cancer Hospital of Fudan University. Because this was a retrospective analysis, patient's consent was not required.

\section{Results}

A total of 917 patients (255 women, 27.81\%, 662 men, $72.19 \%$ ) with primary NSCLC met the inclusion criteria and were analyzed. The mean ( \pm standard deviation) age was $60.15 \pm 9.80$ years, with a range from 20 to 83 years. Of the 917 cases, 339 cases $(36.97 \%)$ were squamous cell carcinomas, 448 cases $(48.85 \%)$ adenocarcinomas, 57 cases $(6.22 \%)$ adenosquamous cell carcinomas, and 35 cases $(3.82 \%)$ large cell carcinomas. The remaining 38 cases $(4.14 \%)$ were other histologic types of primary NSCLC. The tumor was left-sided in 418 cases (45.58\%), right-sided in 499 cases (54.42\%). 522 cases (56.92\%) were upper-lobe, 63 cases $(6.87 \%)$ were middle-lobe, 332 cases (36.21\%) were lower-lobe. Among the 917 cases, 178 (19.41\%) were $\leq 20 \mathrm{~mm}$ in diameter, $214(23.34 \%)$ cases were $20 \sim 30 \mathrm{~mm}, 304$ (33.15\%) cases were $30 \sim 50 \mathrm{~mm}, 143(15.59 \%)$ cases were $50 \sim 70 \mathrm{~mm}$, and $78(8.51 \%)$ cases were $\geq 71 \mathrm{~mm}$. The mean number of $\mathrm{N} 1$ and N2 nodal stations removed are 2.01 and 4.00, respectively. And the mean number of lymph node removed is 18.18. 492 cases of non-small cell lung cancer were found to be NOM0 status. There were 23 cases of stage IV disease. Among these, 4 cases were found to be distant metastases before operation but the patients and family members demanded surgery treatment. And 19 patients were found to have pleural nodules or malignant pleural dissemination at operation. Three cases of NSCLC were found to be N3 at operation.

Univariate analysis revealed that there were no associations between sex, location of lung cancer, pathology and stage distribution, while age and tumor size affected stage distribution significantly. Patients 60 years or older had higher percentages of NOM0 than the ones younger than 60 years $(61.67 \%$ vs. $44.85 \%, \mathrm{p}<0.001)$. Univariate analysis revealed that tumor size affected stage distribution: the smaller the tumor, the more likely the disease was N0M0. The proportion of cases with no metastasis (N0M0) was $53.65 \%$ overall. For tumors $\leq 20 \mathrm{~mm}$ in diameter, the proportion of cases with N0M0 was $70.79 \%$ (95\% confidence interval (CI), 64.11\% 77.47\%), compared to $58.88 \%$ (95\% CI, 52.29\% 65.47\%) for 21 to 30 $\mathrm{mm}, 48.03 \%$ (95\% CI, 42.41\% 53.64\%) for 31 to $50 \mathrm{~mm}$, $47.55 \%$ (95\% CI, $39.15 \% \sim 55.95 \%)$ for 51 to $70 \mathrm{~mm}$, $33.33 \%$ (95\% CI, $22.87 \% \sim 43.79 \%$ ) for $\geq 71 \mathrm{~mm}$ (Table 1 ). The proportions of cases with NOM0 were significantly different between all the successive categories $(p<0.05)$, 
Table 1 Distribution of disease stage according to tumor size

\begin{tabular}{|c|c|c|c|c|c|c|}
\hline \multirow[b]{2}{*}{ Stage of disease } & \multicolumn{5}{|c|}{ Tumor size $(\mathrm{mm})$} & \multirow[b]{2}{*}{ Total } \\
\hline & $\leq 20$ & $21 \sim 30$ & $31 \sim 50$ & $51 \sim 70$ & $\geq 71$ & \\
\hline NOMO & 126 & 126 & 146 & 68 & 26 & 491 \\
\hline N1M0 & 13 & 29 & 48 & 24 & 19 & 133 \\
\hline $\mathrm{N} 2 \mathrm{MO}$ & 32 & 52 & 103 & 49 & 29 & 266 \\
\hline No-2M1/N3M0-1 & 7 & 7 & 7 & 2 & 4 & 27 \\
\hline Total (\% of NOMO) & 178(70.79) & $214(58.88)$ & $304(48.03)$ & $143(47.55)$ & 78(33.33) & $917(53.65)$ \\
\hline
\end{tabular}

except between tumors 31 to $50 \mathrm{~mm}$ and 51 to $70 \mathrm{~mm}$ $(\mathrm{p}=1.00)$. The proportions of cases with NOM0 were statistically significantly different among all the nonconsecutive categories according to tumor size ( $\mathrm{p}<$ 0.05 ). Tumor size did affect the distribution of stage in the multivariate analysis with the following variables entered to the multivariate analysis: gender, age, location of tumor, histology, categories of tumor size.

The mean $( \pm \mathrm{SD})$ tumor size of cases with NOM0 status was $37.17 \pm 21.34 \mathrm{~mm}$, compared to $45.75 \pm 23.19$ $\mathrm{mm}$ for cases with other status. The tumor size of cases with NOMO disease was significantly smaller than all the other cases $(\mathrm{p}<0.01)$.

\section{Discussion}

The proportion of patients dying from lung cancer in China rose $30.4 \%$ from 2000 to 2005 [1,2]. The incidence rate continues to increase due to the high prevalence of smoking and China's large population. Efforts need to be made to detect lung cancer earlier, so patients can live longer.

Proponents of CT screening for lung cancer believe that highly sensitive CT scans may reduce mortality from lung cancer. CT scans reportedly can detect lung cancers with smaller lesions, leading to a significant stage shift from advanced late stage disease to early, more curable stages. According to the new lung cancer staging system, tumor size is an important characteristic of the T descriptors [3]. While more and more studies support that tumor size is an important survival factor in NSCLC [14-17], the association between tumor size and stage distribution is still controversial.

The current study was conducted to analyze the relationship between clinicopathologic factors and disease stage distribution. This study suggests that patients 60 year or older have higher percentage of NOM0 disease than those younger than 60 year $(61.67 \%$ vs. $44.85 \%$, p < 0.001). Several factors may explain this finding. First, higher proportion of older peoples seek and receive a health examination, as they pay more attention to their physical status. Consistent with this, many patients were found to have incidental NSCLC when under evaluation for other diseases. Second, younger patients tend to have more aggressive NSCLC [18]. The third reason for this is elderly patients are less likely than young ones to be offered surgical treatment if the preoperative workup showed a more advanced tumor stage. This observation indicates that we cannot ignore lung cancer screening in younger people.

Studies on the effect of tumor size on disease stage have conflicting results [19-22]. Although recent studies of $\mathrm{CT}$ screening found relatively high percentages of stage I NSCLC (70\% 87\%) [23-25], Swensen found no statistically significant stage shift. He explained that the high percentage of detected stage I lung cancers may be due to a larger number of indolent cancers being detected [26]. To test the presumption that smaller lesions represent earlier stage diseases, Heyneman and his colleagues conducted an analysis including 620 cases who presented with pathologically proven primary NSCLC measuring $\leq 3 \mathrm{~cm}$ [19]. They found no statistically significant differences in distribution of disease stage according to tumor size categories. They asserted that CT screening may not result in a shift from advanced stage to earlier stage distribution. However, cases from the study cohort were collected over a 20 year period and included only 25 cases with tumor sizes $<1 \mathrm{~cm}$, while the percentage of stage I cases was very high for all categories of tumor sizes. These factors may lower the power to detect a relationship between tumor size and disease stage. Henschke and colleagues demonstrated an association between tumor size and stage distribution in either symptomatic or asymptomatic patients $[20,21]$. One study utilizing the Surveillance, Epidemiology, and End Results database including 84152 cases primary NSCLC revealed that tumor size did have an effect on disease stage distribution: the smaller the tumor, the more likely the disease was stage I [20]. In another study performed by the I-ELCAP investigators, Henschke concluded that lymph node status had a strong relationship to tumor diameter for NSCLC in screen-diagnosed lung cancers: the percentage of NOMO cases was higher in patients with smaller tumors [21]. Flieder and his colleagues demonstrated that NSCLC measuring $21 \sim 30 \mathrm{~mm}$ was twice as likely to have nodal metastases as carcinomas $\leq 20 \mathrm{~mm}$ [22].

Our study suggests that there is a relationship between tumor size and disease stage of NSCLC: the 
percentage of NOM0 disease decreased with increasing tumor diameter. The proportion of NOM0 disease was 70.79\% (95\% CI, 64.11\% 77.47\%) for tumors $\leq 20 \mathrm{~mm}$, compared to $58.88 \%$ (95\% CI, $52.29 \% \sim 65.47 \%$ ) for 21 to $30 \mathrm{~mm}, 48.03 \%$ (95\% CI, 42.41\% 53.64\%) for 30 to 50 $\mathrm{mm}, 47.55 \%$ (95\% CI, 39.15\% 55.95\%) for 51 to $70 \mathrm{~mm}$, $33.33 \%$ (95\% CI, $22.87 \% \sim 43.79 \%$ ) for $\geq 71 \mathrm{~mm}$. The gradients in the successive percentages of NOM0 were significantly different $(\mathrm{p}<0.05)$, except between tumors 31 to $50 \mathrm{~mm}$ and 51 to $70 \mathrm{~mm}(\mathrm{p}=1.00)$ (Figure 1). The percentage of NOM0 disease for category of $\leq 20 \mathrm{~mm}$ was significantly higher than all the other categories ( $p$ $<0.05$ ), and the gradients in all the non-successive percentages of NOM0 disease were significantly different ( $p$ $<0.05$ ). The tumor size of cases with N0M0 was significantly smaller than all the other cases $(\mathrm{p}<0.01)$. Logistic regression model determined the true effect of tumor size on stage distribution.

The current study was different from previous studies [19-21]. In previous studies, thoracic CTs had an accuracy of only $75 \% \sim 80 \%$ in assessing mediastinal lymph nodes in NSCLC patients [27]. Lymph node metastasis was recognized even in clinical T1N0M0 lung cancers smaller than $2 \mathrm{~cm}$ [28]. 39\% cases showed a mismatch between clinical diameter based on thoracic CT and postsurgical diameter [28]. These factors may lower the accuracy of the results of previous studies. The status of stage and tumor diameter in cases from our study was more accurate than in previous studies, which included cases whose staging and size of lesions were determined only based on clinical examinations. All cases in our study cohort received surgical treatment, and postsurgical pathologic stage and tumor diameter were obtained from pathology reports. However, as in previous studies, our study has a selection bias by including symptomatic and asymptomatic patients. As Henschke said, compared with large tumors, smaller tumors are more likely to be symptomatic due to their lymph node or distant metastases. As smaller tumors are not likely to cause local symptoms and would remain mostly undetected unless they have disseminated, while large cancers are more likely to be symptomatic due to local invasion or compression. This may dilute the size/stage relationship within our database relative to that in a screening database. Our study cohort also included only those who underwent an operation, which could be another source of bias.

The percentage of N2 disease in the 5 categories of our study is higher than the result reported in the IASLC database [29], probably because of a sparse use of invasive staging procedures or PET-CT examination before operation, especially before 2004 in the Cancer Hospital of Fudan University.

The median diameter of lesions missed by chest radiography was $16 \mathrm{~mm}[30,31]$, while the median diameter of primary lung cancers detected by CT screening was $15 \mathrm{~mm}$ [10-12,24-26]. Sone and colleagues reported that the miss rate of lung cancers $\leq 2 \mathrm{~cm}$ on chest radiography was $79 \%$ [32]. The mean size of lung cancer lesions detected by chest radiography was $3 \mathrm{~cm}$ [33]. In conclusion, our study suggests that tumor size at diagnosis has a definite effect on the stage distribution of NSCLC:

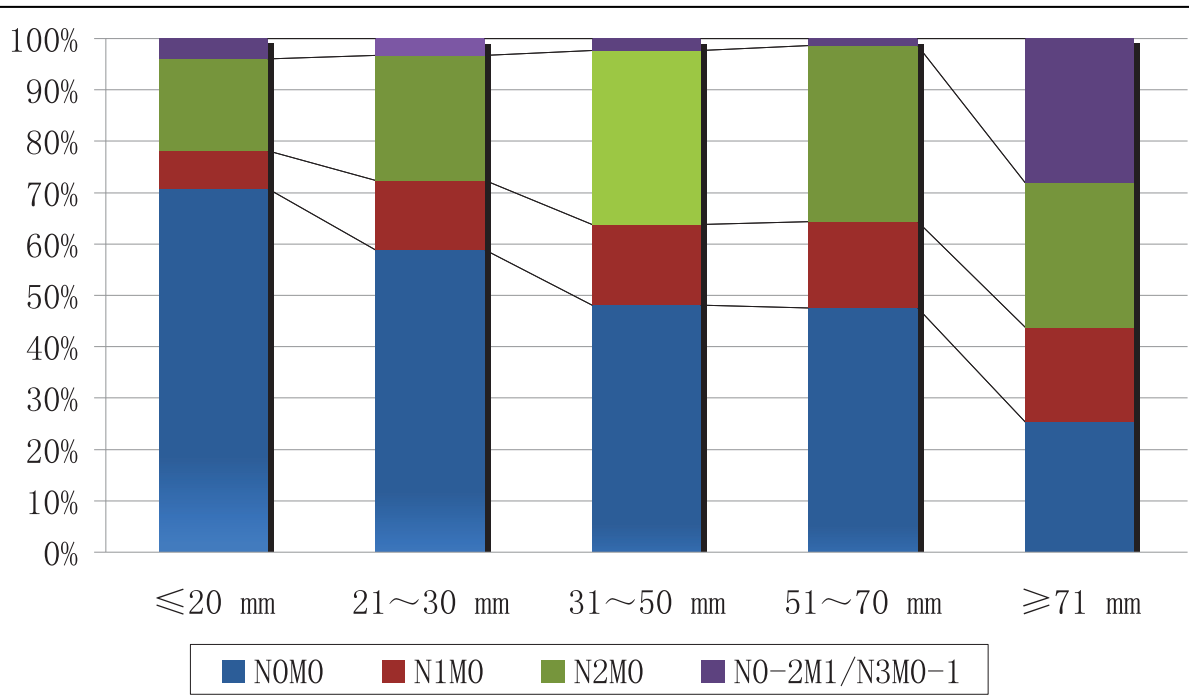

Figure 1 Proportions of disease stage according to tumor size. The percentage of N0M0 disease decreased with the increasing of tumor diameter. The proportion of cases with NOMO was $70.79 \%$ for tumor $\leq 20 \mathrm{~mm}$, compared to $58.88 \%$ for 21 to $30 \mathrm{~mm}$, $48.03 \%$ for 31 to $50 \mathrm{~mm}$, $47.55 \%$ for 51 to $70 \mathrm{~mm}, 33.33 \%$ for $\geq 71 \mathrm{~mm}$. The proportions of cases with N0M0 were significantly different between all the successive categories ( $p<0.05$ ), except between tumors 31 to $50 \mathrm{~mm}$ and 51 to $70 \mathrm{~mm}(p=1.00)$. 
smaller lesions represent earlier stage disease. CT screening can detect smaller lesions that represent more early stage lung cancer.

\section{Conclusions}

Tumor size has a definite effect on stage of NSCLC: smaller lesions represent earlier stage disease.

\section{Abbreviations}

Cl: confidence interval; CT: computed tomography; NSCLC: non-small cell lung cancer; SD: Standard deviation.

\section{Acknowledgements}

This research was supported partially by the Shanghai Municipal Natural Science Fund (06DZ19503), Shanghai Municipal Natural Science Fund (09JC1416302), in the study design, collection and analysis.

\section{Author details}

'Department of Thoracic Surgery, Fudan University Shanghai Cancer Center, 270 Dong'an Road, Shanghai 200032, China. ${ }^{2}$ Department of Oncology, Shanghai Medical College, Fudan University, 270 Dong'an Road, Shanghai 200032, China

\section{Authors' contributions}

FY contributed to the design, acquisition of data, analysis of data, and drafting the manuscript. HQC contributed to conception, design, revised the article critically for important intellectual content, and provided final approval of the version to be published. JQX contributed to conception and interpretation of data. YWZ contributed to conception and interpretation of data. JHZ contributed to acquisition of data. HH contributed to acquisition of data. JZ contributed to analysis of data. XYL contributed to acquisition of data. All authors read and approved the final version of the manuscript.

\section{Competing interests}

All the authors declare that they have no actual or potential competing interests including any financial, personal or other relationships with other people or companies/organizations that could inappropriately influence this article.

Received: 28 February 2010 Accepted: 2 September 2010

Published: 2 September 2010

\section{References}

1. Yang L, Li LD, Chen YD, Parkin DM: Cancer incidence and mortality estimates and prediction for year 2000 and 2005 in China. Chin J of Health Statistics 2005, 22:218-221, 231.

2. Yang L, Li LD, Chen YD, Pakin DM: Mortality time trends and the incidence and mortality estimation and projection for lung cancer in China. Chin J of Lung Cancer 2005, 8:274-278.

3. Detterberk FC, Boffa DJ, Tanoue LT: The New Lung Cancer Staging System. Chest 2009, 136:260-271.

4. Jemal A, Tiwari RC, Murray T, Ghafoor A, Samuels A, Ward E, Feuer EJ, Thun MJ: Cancer statistics, 2004. CA Cancer J Clin 2004, 54:8-29.

5. Molina JR, Adjei AA, Jett JR: Advances in chemotherapy of non-small cell lung cancer. Chest 2006, 130:1211-1219.

6. Alberg AJ, Ford JG, Samet JM: Epidemiology of lung cancer: ACCP evidence-based clinical practice guidelines (2nd Edition). Chest 2007, 132:29S-55S

7. Brett GZ: The value of lung cancer detection by six-monthly chest radiography. Thorax 1968, 23:414-420

8. Fontana RS, Sanderson DR, Woolner LB, Taylor WF, Miller WE, Muhm JR: Lung cancer screening: the Mayo program. J Occup Med 1986, 28:746-750.

9. Kubik A, Polak J: Lung cancer detection: results of a randomized prospective study in Czechslovakia. Cancer 1986, 57:2427-2437.

10. Henschke Cl, McCauley DI, Yankelevitz DF, Naidich DP, McGuinness G, Miettinen OS, Libby DM, Pasmantier MW, Koizumi J, Altorki NK, Smith JP:
Early lung cancer action project: overall design and findings from baseline screening. Lancet 1999, 354:: 99-105.

11. Henschke Cl: Early Lung cancer action project: overall design and findings from baseline screening. Cancer 2000, 89:2474-2482.

12. Sobue BT, Moriyama N, Kaneko M, Kusumoto M, Kobayashi T, Tsuchiya R, Kakinuma R, Ohmatsu H, Nagai K, Nishiyama H, Matsui E, Eguchi K: Screening for lung cancer with low-dose helical computed tomography: anti-lung cancer association project. J of Clin Oncol 2002, 20:911-920.

13. Rami-Porta R, Ball D, Crowley J, Giroux DJ, Jett J, Travis WD, Tsuboi M, Vallieres E, Goldstraw P: The IASLC lung cancer staging project: proposals for the revision of the T descriptors in the forthcoming (seventh) edition of the TNM classification for lung cancer. J of Thorac Oncol 2007, 2:593-602.

14. Wisnivesky JP, Yankelevitz D, Henschke Cl: The effect of tumor size on curability of stage I non-small cell lung cancers. Chest 2004, 126:761-765.

15. Mery CM, Pappas AN, Burt BM, Bueno R, Linden PA, Sugarbaker DJ, Jaklitsch M: Diameter of non-small cell lung cancer correlates with longterm survival. Implications for T stage. Chest 2005, 128:3255-3260.

16. Ou SH, Zell JA, Ziogas A, Anton-Culver H: Prognostic factors for survival of stage I nonsmall cell lung cancer patients: a population-based analysis of 19702 stage I patients in the California cancer registry from 1989 to 2003. Cancer 2007, 110:1532-1541.

17. Lopez-Encuentra A, Duque-Medina JL, Rami-Porta R, Camara AG, Ferrando P: Staging in lung cancer: is $3 \mathrm{~cm}$ a prognostic threshold in pathologic stage I non-small cell lung cancer? A multicenter study of 1020 patients. Chest 2002, 121:1515-1520.

18. Tammemagi CM, Freedman Mt, Church TR, Oken MM, Hocking WG, Kvale PA, Hu P, Riley TL, Ragard LR, Prorok PC, Berg CD: Factors associated with human small aggressive non-small cell lung cancer. Cancer Epidemiol Biomarkers Prev 2007, 16:2082-2089.

19. Heyneman LE, Herndon JE, Goodman PC, Patz EF: Stage distribution in patients with a small $(\leq 3 \mathrm{~cm})$ primary nonsmall cell lung carcinoma. Implication for lung carcinoma screening. Cancer 2001, 92:3051-3055.

20. Wisnivesky JP, Yankelevitz D, Henschke Cl: Stage of lung cancer in relation to its size. Part 2. Evidence. Chest 2005, 127:1136-1139.

21. Henschke Cl, Yankelevitz DF, Miettinen OS: The International Early Lung Cancer Action Program Investigators: Computed tomography screening for lung cancer: the relationship of disease stage to tumor size. Arch Intern Med 2006, 166:321-325.

22. Flieder DB, Port JL, Korst RJ, Christos PJ, Levin MA, Becker DE, Altorki NK: Tumor size is a determinant of stage distribution in T1 non-small cell lung cancer. Chest 2005, 128:2304-2308.

23. Diederich S, Thomas M, Semik M, Lenzen H, Roos N, Weber A, Heindel W, Wormanns D: Screening for early lung cancer with low-dose spiral computed tomography: results of annual follow-up examinations in asymptomatic smokers. Eur Radiol 2004, 14:691-702.

24. Henschke Cl, Yankelevitz DF, Libby DM, Pasmantier MW, Smith JP, Miettinen OS: The International Early Lung Cancer Action Program Investigators: Survival of patients with stage I lung cancer detected on CT screening. N Eng J Med 2006, 355:1763-1772.

25. New York Early Lung Cancer Action Project Investigators: CT screening for lung cancer: diagnoses resulting from the New York Lung Cancer Action Project. Radiology 2007, 243:239-249.

26. Swensen SJ, Jett JR, Hartman TE, Midthun DE, Mandrekar SJ, Hillman SL, Sykes AM, Aughenbaugh GL, Bungum AO, Allen KL: CT screening for lung cancer: five-year prospective experience. Radiology 2005, 235:259-265.

27. Kramer $\mathrm{H}$, Groen HJM: Current concepts in the mediastinal lymph node staging of non-small cell lung cancer. Ann Surg 2003, 238:180-188.

28. Koike T, Terashima M, Takizawa T, Watanable T, Kurita Y, Yokoyama A: Clinical analysis of small-sized peripheral lung cancer. J of Thorac and Cardiovasc Surg 1998, 115:1015-1020.

29. Goldstraw P, Crowley J, Chansky K, Giroux DJ, Groome PA, Rami-Porta R, Postmus PE, Rusch V, Sobin L: The IASLC lung cancer staging project: proposals for the revision of the TNM stage groupings in the forthcoming (seventh) edition of the TNM classification of malignant tumours. J of Thorac Oncol 2007, 2:706-714.

30. Quekel LG, Kessels AG, Goei R, van Engelshoven JM: Miss rate of lung cancer on the chest radiography in clinical practice. Chest 1999, 115:720-724 
31. Austin JH, Romney BM, Goldsmith LS: Missed bronchogenic carcinoma: radiologic findings in 27 patients with a potentially resectable lesion evident in retrospect. Radiology 1992, 182:115-122.

32. Sone S, Li F, Yang ZG, Takashima S, Maruyama Y, Hasegawa M, Wang JC, Kawakami S, Honda T: Characteristics of small lung cancers invisible on conventional chest radiography and detected by population based screening using spiral CT. Br J of Radiol 2000, 73:137-145.

33. Jett JR, Midthun DE: Screening for lung cancer: current status and future directions. Chest 2004, 125:158S-162S

\section{Pre-publication history}

The pre-publication history for this paper can be accessed here: http://www.biomedcentral.com/1471-2407/10/474/prepub

doi:10.1186/1471-2407-10-474

Cite this article as: Yang et al:: Relationship between tumor size and

disease stage in non-small cell lung cancer. BMC Cancer 2010 10:474.

\section{Submit your next manuscript to BioMed Central} and take full advantage of:

- Convenient online submission

- Thorough peer review

- No space constraints or color figure charges

- Immediate publication on acceptance

- Inclusion in PubMed, CAS, Scopus and Google Scholar

- Research which is freely available for redistribution

Submit your manuscript at www.biomedcentral.com/submit 